\section{Commentary: Percutaneous supraclavicular subclavian intra-aortic balloon pump insertion-A straighter route to fewer complications?}

\author{
Morgan K. Moroi, MD, and Koji Takeda, MD, PhD
}

Intra-aortic balloon pumps (IABPs) are circulatory support devices that may potentially improve coronary and systemic perfusion in patients with cardiogenic shock. The goal is to provide sufficient stabilization to allow for myocardial recovery or successful bridge to durable therapy, such as left ventricular assist device implantation or heart transplantation. ${ }^{1}$ Despite its ancient form of mechanical support, there is enthusiasm toward IABP use, especially after the heart allocation policy change in $2018 .^{2}$

Conventionally, the femoral artery is used for IABP insertion, given ease of access. However, due to location, an important disadvantage is the inability of the patient to ambulate. This increases the risk of debilitation and may become a critical issue for recovery from destination therapy. ${ }^{3-6}$

Given this limitation, alternative approaches have been explored. Current techniques include surgical and percutaneous IABP placement via the axillary or subclavian artery. These approaches provide patients with mechanical hemodynamic support while also enabling patients to mobilize and participate in physical therapy. ${ }^{3-6}$

The first IABP placement involving the axillary artery was performed in 1989 using a modified surgical

\footnotetext{
From the Division of Cardiothoracic Surgery, Department of Surgery, Columbia University Medical Center-New York Presbyterian Hospital, New York, NY. Disclosures: The authors reported no conflicts of interest.

The Journal policy requires editors and reviewers to disclose conflicts of interest and to decline handling or reviewing manuscripts for which they may have a conflict of interest. The editors and reviewers of this article have no conflicts of interest.

Received for publication April 12, 2021; revisions received April 12, 2021; accepted for publication April 22, 2021; available ahead of print April 27, 2021.

Address for reprints: Koji Takeda, MD, PhD, Division of Cardiothoracic Surgery, Department of Surgery, Columbia University Medical Center-New York Presbyterian Hospital, 177 Fort Washington Ave, 7GN-435, New York, NY 10032 (E-mail: kt2485@cumc.columbia.edu).

JTCVS Techniques 2021;8:25-6

2666-2507

Copyright (C) 2021 Published by Elsevier Inc. on behalf of The American Association for Thoracic Surgery. This is an open access article under the CC BY-NC-ND license (http://creativecommons.org/licenses/by-nc-nd/4.0/).

https://doi.org/10.1016/j.xjtc.2021.04.028
}

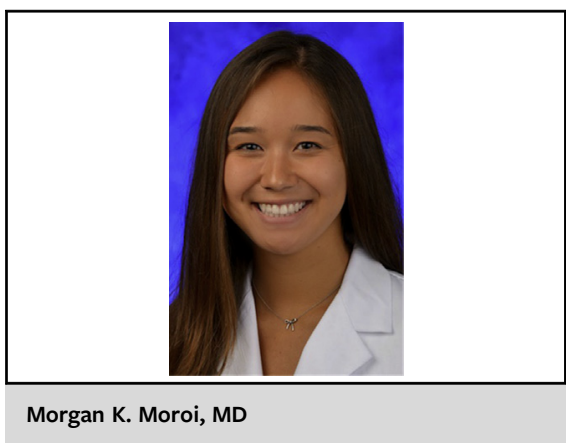

CENTRAL MESSAGE

Percutaneous supraclavicular subclavian intra-aortic balloon pump (IABP) placement is a viable insertion technique that may allow for reduced rates of device kinking and migration.

technique. ${ }^{7}$ Currently, transaxillary access can be obtained percutaneously using sonographic guidance and Seldinger's technique, which is less invasive and does not require general anesthesia. Alternatively, a Dacron side-arm graft can be surgically placed to avoid trauma to the axillary artery and facilitate controlled decannulation by simply transecting the graft. Similar techniques can also be employed with the subclavian artery.

Unfortunately, these alternative modes of IABP access are also not without risk. Most notably, axillary or subclavian IABPs can be associated with driveline kinking, device migration, and device malfunction, with some studies reporting incidence as high as $40 \% .^{3-6}$ In our practice, this tends to be associated with aortic arch anatomy, as we have seen patients with steeper angles at the subclavianaortic junction more frequently experience kinking and migration. For these patients, we occasionally position the IABP more inferiorly to reduce the likelihood of these complications.

Here, Song and Jeevanandam ${ }^{8}$ present a new technique for percutaneous subclavian IABP insertion with the much-needed focus of reducing the incidence of kinking and migration. The authors approach the subclavian artery from the supraclavicular fossa and use Seldinger's technique to access the vessel. The IABP is then introduced with a long wire-reinforced sheath and positioned appropriately. Removal of IABP is performed with either a percutaneous closure device or by manually holding pressure. 
The authors anecdotally report that the straighter course to the descending aorta from the subclavian artery allows the IABP to be positioned with reduced risk of kinking and migration. Further, they report that the wirereinforced introducer plays a critical role in reducing these events. Before using the wire-reinforced sheath, the authors experienced kinking at the level of the distal arch. However, with this sheath, Song and Jeevanandam share that kinking and migration events were rare. Should this technique reduce these events, this approach should be kept in mind as a viable, safe, and potentially preferred method of IABP insertion. We look forward to an upcoming analysis of outcomes related to this technique.

\section{References}

1. Fried JA, Nair A, Takeda K, Clerkin K, Topkara VK, Masoumi A, et al. Clinical and hemodynamic effects of intra-aortic balloon pump therapy in chronic heart failure patients with cardiogenic shock. J Heart Lung Transplant. 2018;37:1313-21.
2. Huckaby LV, Seese LM, Mathier MA, Hickey GW, Kilic A. Intra-aortic balloon pump bridging to heart transplantation. Circ Heart Fail. 2020;13: e006971.

3. Umakanthan R, Hoff SJ, Solenkova N, Wigger MA, Keebler ME, Lenneman A, et al. Benefits of ambulatory axillary intra-aortic balloon pump for circulatory support as bridge to heart transplant. J Thorac Cardiovasc Surg. 2012;143: 1993-7.

4. Estep JD, Cordero-Reyes AM, Bhimaraj A, Trachtenberg B, Khalil N, Loebe M, et al. Percutaneous placement of an intra-aortic balloon pump in the left axillary/ subclavian position provide safe ambulatory long term support as bridge to heart transplantation. JACC Heart Fail. 2013;143:382-8.

5. Bhimaraj A, Agrawal T, Duran A, Tamimi O, Amione-Guerra J, Trachtenberg B, et al. Percutaneous left axillary artery placement of intraaortic balloon pump in advanced heart failure patients. JACC Heart Fail. 2020;8:324-6.

6. Nishida H, Koda Y, Kalantari S, Nguyen A, Chung B, Grinstein J, et al. Outcomes of ambulatory axillary intraaortic balloon pump as a bridge to heart transplantation. Ann Thorac Surg. 2021;111:1264-70.

7. McBride LR, Miller LW, Naunheim KS, Pennington DG. Axillary artery insertion of an intra-aortic balloon pump. Ann Thorac Surg. 1989;48:874-5.

8. Song TH, Jeevanandam V. Technique of percutaneous supraclavicular subclavian intra-aortic balloon pump placement. J Thorac Cardiovasc Surg Tech. 2021;8: 20-2. 